\title{
Interventions for hearing and vision impairment to improve outcomes for people with dementia: a scoping review
}

DOI:

$10.1017 / \mathrm{S} 1041610218000728$

\section{Document Version}

Accepted author manuscript

Link to publication record in Manchester Research Explorer

\section{Citation for published version (APA):}

Dawes, P., Wolski, L., Himmelsbach, I., Regan, J., \& Leroi, I. (2018). Interventions for hearing and vision impairment to improve outcomes for people with dementia: a scoping review. International Psychogeriatrics, 1-19. https://doi.org/10.1017/S1041610218000728

\section{Published in:}

International Psychogeriatrics

\section{Citing this paper}

Please note that where the full-text provided on Manchester Research Explorer is the Author Accepted Manuscript or Proof version this may differ from the final Published version. If citing, it is advised that you check and use the publisher's definitive version.

\section{General rights}

Copyright and moral rights for the publications made accessible in the Research Explorer are retained by the authors and/or other copyright owners and it is a condition of accessing publications that users recognise and abide by the legal requirements associated with these rights.

\section{Takedown policy}

If you believe that this document breaches copyright please refer to the University of Manchester's Takedown Procedures [http://man.ac.uk/04Y6Bo] or contact uml.scholarlycommunications@manchester.ac.uk providing relevant details, so we can investigate your claim.

\section{OPEN ACCESS}


Interventions for hearing and vision impairment to improve outcomes for people with dementia: A scoping review

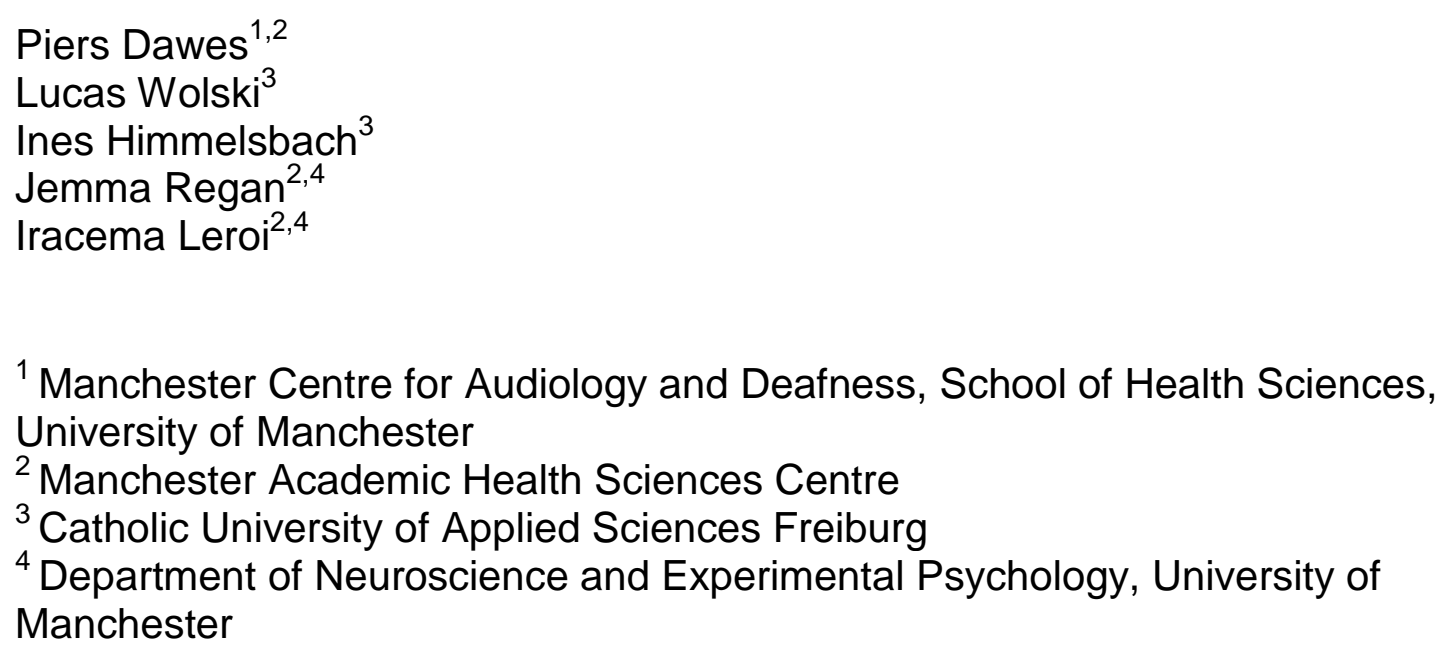

${ }^{1}$ Manchester Centre for Audiology and Deafness, School of Health Sciences, University of Manchester

${ }^{2}$ Manchester Academic Health Sciences Centre

${ }^{3}$ Catholic University of Applied Sciences Freiburg

${ }^{4}$ Department of Neuroscience and Experimental Psychology, University of Manchester

Correspondence should be addressed to: Dr Piers Dawes, Manchester Centre for Audiology and Deafness, School of Health Sciences, University of Manchester, M13 9PL, UK. Phone: +44 161306 1758. Email Piers.dawes@manchester.ac.uk 


\section{Abstract}

Background: Age-related hearing and vision problems are common among people with dementia and are associated with poorer function, reduced quality of life and increased caregiver burden. Addressing sensory impairments may offer an opportunity to improve various aspects of life for people with dementia.

Methods: Electronic databases were searched using key terms dementia, hearing impairment, vision impairment, intervention and management. Database searches were supplemented by hand searching bibliographies of papers and via consultation with a network of health professional experts. Studies were eligible for inclusion if they included adults aged over 50 with dementia with adult-onset hearing or vision impairment who had received a hearing or vision intervention in relation to cognitive function, rate of decline, psychiatric symptoms, hearing/vision-related disability, quality of life and/or caregiver burden outcomes. A range of study designs were included. Results were summarised descriptively according to level of evidence and effect sizes calculated where possible. Risk of bias was assessed using Downs \& Black's (1998) checklist. The development of the intervention was summarised according to the CReDECI2 scheme. PROSPERO review registration number 2016:CRD42016039737.

Results: Twelve papers describing hearing interventions and five papers describing vision interventions were included. Most were of low to moderate quality. One high quality randomised controlled trial of a hearing aid intervention was identified. Hearing interventions included provision of hearing aids, assistive listening devices, communication strategies, hearing aid trouble shooting, and cochlear implantation. Vision interventions included prism lenses, rehabilitation training, and cataract surgery. There was no consistent evidence for the positive impact of hearing/vision interventions on cognitive function, rate of cognitive decline, quality of life or caregiver burden.

Conclusion: Sensory interventions may promote better outcomes, but there is a need for properly powered, controlled trials of hearing and vision interventions on outcomes relevant to people living with dementia. 
Keywords: hearing impairment, presbycusis, vision impairment, dementia, intervention, management, non-pharmacological treatment 


\section{Introduction}

In the near future, the number of people with dementia is likely to rise significantly across the globe, so improved treatment and care for people with dementia has been identified as an international priority (Alzheimer's Disease International, 2016). Nonpharmacological interventions can be effective in improving quality of life, reducing behavioural and psychological symptoms of dementia and reducing the burden on caregivers (Cooper et al., 2012; Douglas et al., 2004). Such interventions that address hearing and vision impairment among people with dementia are of particular interest due to: the high prevalence of acquired hearing and vision impairment among people with dementia; the negative impact of sensory impairment on dementia-related outcomes for the individual and their care partner; the ease of detection of sensory impairments; the effectiveness of interventions in reducing hearing/vision disability; the low cost and the ready availability of interventions for sensory impairment; and the potential health economic benefits of intervening.

Surveys indicate very high levels of hearing and vision impairment among people with cognitive impairment. In a 2003 UK study (Allen et al.), 87\% of communitydwelling adults with mild-to-moderate levels of dementia had hearing impairment (pure tone thresholds $>40 \mathrm{~dB} \mathrm{HL}$ ). A recent national survey of vision impairment among adults with dementia aged $60-89$ years in the UK estimated that $32.5 \%$ had presenting visual acuity worse than $6 / 12$ (Bowen et al., 2016). Among those living in residential care, $51.4 \%$ had visual acuity worse than $6 / 12$. Surveys also indicate that both hearing and vision impairments go undetected and untreated. Hearing impairment was undetected and untreated in $80 \%$ of people with dementia living in the community (Allen et al., 2003) and in 50\% of people living in a residential home (Cohen-Mansfield and Taylor, 2004). In the UK, 14\% of people with dementia were using outdated refractive prescriptions and $48 \%$ of post-refraction visual impairment among people with dementia was due to cataracts, a treatable cause of vision impairment (Bowen et al., 2016). In spite of this, it is feasible to reliably identify hearing and vision impairments in the majority of people with dementia (Morse et al., 2004; Uhlmann et al., 1989). Treatments for sensory impairment are effective in improving function and quality of life in adults with unimpaired cognition (Brenner et al., 1993; Chisolm et al., 2007), and are relatively low in cost (Chao and Chen, 2008; 
Lansingh et al., 2007; Vitale et al., 2006), particularly compared to the costs associated with dementia care (Alzheimer's Society, 2015).

Hearing and vision impairment in elderly people is often associated with negative outcomes, including difficulties in performing activities of daily living, lower quality of life, reduced physical and social activity, increased stress and burden on friends and family, reduced mental well-being (Horowitz, 2004; Strawbridge et al., 2000) and auditory and visual hallucinations (Sanchez et al., 2011; Teunisse et al., 1996). Sensory impairments may exacerbate existing problems due to cognitive impairment, thereby reducing quality of life and functional ability while increasing caregiver burden and the likelihood of institutionalisation (Heyl and Wahl, 2012; Palmer et al., 1998).

The objective of this scoping review was to synthesise the evidence base regarding the effect of treatment of hearing and vision impairment in people living with dementia on the following outcomes: (i) cognition; (ii) rate of cognitive decline; (iii) behavioural and psychological symptoms of dementia; (iv) hearing or vision-related quality of life; (v) general quality of life; (vi) activities of daily living; and (vii) caregiver burden for adults with dementing conditions. Due to the small evidence base, studies using a range of designs were included.

\section{Methods}

The protocol for this study was listed with the PROSPERO international register of systematic reviews (registration number 2016:CRD42016039737). Due to the lack of randomised controlled trials in this area, scoping review methodology was selected as the most appropriate means of analysis. Scoping reviews encompass various study designs and broader subject material than systematic reviews (Arksey and O'Malley, 2005). They do not focus on study quality, but instead explore the breadth and depth of the existing research to identify areas requiring further investigation (Davis et al., 2009). Acquisition, extraction, assessment and reporting of the data in the present review was carried out according to the Preferred Reporting Items for Systematic Reviews and Meta-Analysis (PRISMA) Statement (Moher et al., 2009).

\section{Eligibility criteria}


Studies were eligible for inclusion if they included adult participants who were: (i) resident in community or institutional settings; (ii) aged over 50 years (to differentiate from atypical young onset dementia) and (iii) diagnosed with a progressive neurodegenerative condition leading to dementia, including 'mild cognitive impairment' (MCl; defined according to Petersen criteria; Petersen, 2011), 'dementia' (National Institute of Neurological and Communicative Disorders and Stroke criteria) including Parkinson's disease dementia, frontotemporal dementia, vascular dementia and Alzheimer disease or dementia due to other causes. Additionally, participants must have had either: (i) acquired adult-onset hearing loss, including neurosensory or conductive hearing loss (determined by audiological testing (e.g. hearing levels over >40 dB HL; at 2-6 kHz (http://www.who.int/pbd/deafness/hearing impairment grades/en/), or self-reported hearing problem); or (ii) acquired adult-onset vision impairment due to any vision pathology including cataracts, age related macular degeneration, glaucoma, diabetic retinopathy or other pathology. Visual impairment must have been determined by optometric testing (e.g. visual acuity of $<0.3$ dioptre and/or visual field of $<30^{\circ}$ according to WHO/ICD-10 low vision criteria (http://www.icd10data.com/ICD10CM/Codes/H00-H59/H53-H54/H53-)) or have been self-reported.

Inclusion criteria for the hearing and vision interventions necessitated the participants having received at least one intervention by a suitably qualified individual (audiologist/otolaryngologist, optometrist/ophthalmologist or hearing/vision rehabilitation worker). Treatments may have been received in any setting including hospital, clinic or community base. The following interventions were included: (i) surgical management (e.g. for otosclerosis); (ii) ear hygiene (including wax removal and treatment of chronic middle ear infection); (iii) assistive devices (including hearing aids, cochlear implants and other assistive listening devices): (iv) hearing tactics; or (v) environmental modifications. Interventions for vision impairment included were: (i) surgical intervention (including anti-vascular endothelial growth factor therapy in macular degeneration; (ii) laser surgery in cataracts and glaucoma); (ii) assistive devices (including corrective refraction, talking barcode scanners, colour helpers); (iii) environmental modifications (including room lighting); or (iv) vision 
tactics (including problem solving training, behavioural training, resource activation or mobility training).

Randomised controlled trials, quasi-experimental studies and observational studies were included. For those studies with comparison conditions, the comparison could have included placebo/sham, standard care, alternative intervention or no intervention. Process evaluation studies that did not include outcomes of the intervention were excluded due to the focus of the review being on the outcomes of sensory interventions for people with dementia, rather than the development, implementation or delivery of sensory interventions.

Outcome measures of interest were: (i) cognitive performance (as measured with standardised assessments); (ii) rate of decline (defined as change in cognitive performance, institutionalisation or death); (iii) behavioural and psychological symptoms (including agitation, aggression, psychosis and apathy; (measured with standardised assessments); (iv) hearing or vision-related disability (measured with standardised assessments of hearing/vision disability, e.g. Hearing Handicap Inventory for the Elderly (HHIE; Ventry and Weinstein, 1982), Visual Functioning Questionnaire-25 (VFQ-25; Mangione et al., 1998)); (v) quality of life (measured with standardised assessments, e.g. Health Utilities Index-3; Furlong et al., 2001): (vi) activities of daily living (including both instrumental activities and activities of daily living measured with standardised checklists); and (vii) caregiver burden (measured with standardised assessments, e.g. Zarit Burden Interview; Zarit et al.,1985). Adverse effects or complications of interest included non-adherence or nonacceptance of interventions, including non-use of assistive devices.

Studies were included if published in any official language of the European Union, with no restriction on publication date. Both peer reviewed studies and articles from the grey literature were included. Editorials, newspaper articles and other forms of popular media were excluded. Studies were not selected on the basis of methodological quality.

\section{Data sources}


The search strategy included: (i) computer searches of electronic databased; (ii) consultation with an expert network; and (iii) hand-searching the reference lists of eligible papers for additional studies.

The computer search was carried out with Google Scholar, PubMed, Cochrane Central Register of Controlled Trials (CENTRAL), PsycINFO, CINAHL, ComDisDome, Agelnfo, Web of Science, Scopus, Open Grey and clinical trials registers ClinicalTrials.gov and the WHO international clinical trials registry platform (ICTRP). Search terms were: dementia AND (sight OR vision OR hearing OR deaf*) AND (rehabilitation OR intervention OR management OR treatment OR outcome). The computer search was carried out during August 2016. Prior to submission of the manuscript, the computer search was re-run in June 2017 to identify any new studies. There was no restriction on the publication date; the search period included the earliest possible date in available each database until the date of the search.

To ensure that all available relevant studies were captured in our review, w undertook an international consultation with 53 clinical and/or academic experts in the fields of psychiatry, geriatric medicine, psychology, neurology, audiology/otolaryngology and optometry/ophthalmology in the US, the UK, France, Greece, Cyprus, Germany, Norway, the Netherlands and Demark. The experts were contacted via email and asked whether they were aware of any relevant published, unpublished or on-going studies that were not identified on the basis of the computer search. Four professionals offered additional suggestions. Finally, hand searching of the reference lists of all papers eligible for inclusion in the review was carried out to identify further studies of interest.

\section{Study selection}

Step 1: Study titles were independently reviewed by the authors and selected for further review if the title included mention of evaluation of intervention or management of hearing or vision impairment in adults with cognitive impairment (including dementia or mild cognitive impairment). Step 2: Abstracts were independently reviewed by the first and second authors (PD and LW) and selected for further review based on the same criteria as step 1. If a consensus was not 
reached, the full text of the paper was reviewed. Step 3: Full-text articles of abstracts selected in Step 2 were reviewed by the first and second authors. Disagreements were discussed with additional authors. Full-text articles were reviewed according to the eligibility criteria described above. The study selection process and reasons for exclusion were recorded (Figure 1).

(insert Figure 1)

\section{Data extraction and analysis}

Data extraction was based on the parameters listed in table 1, including participant details, intervention type, and outcome measure. Data were extracted from the fulltext article by reviewer PD and reviewed by a second reviewer (LW). Disagreements were recorded and resolved by involvement of an additional reviewer.

Results were summarised descriptively according to whether there was a reported improvement, deterioration, or no change in each respective outcome measure. Where the necessary statistics were reported, effect sizes (Cohen's $d$ ) for statistically significant changes were calculated with a view to summarise the effects of hearing/vision intervention for each outcome variable if sufficient data on effect sizes were available. Heterogeneity of study design and outcomes of interest, use of informal outcome measures and lack of reporting of the required statistics precluded statistical synthesis of results across studies.

Study design was described according to the Oxford 2011 Levels of Evidence (OCEBM Levels of Evidence Working Group, 2011, which are: Level 1, fully powered randomised controlled trials or meta-analysis; Level 2, controlled trials without randomisation; Level 3, retrospective cohort or case-control studies; Level 4, case series or uncontrolled single group study; and Level 5, expert opinion or case report). Risk of bias was assessed using Downs \& Black's (1998) checklist for assessing the quality of randomised and non-randomised studies. The checklist contains 27 items pertaining to the quality of reporting, internal and external validity and statistical power with a maximum possible score of 30. Data concerning the development, piloting and evaluation of the sensory interventions were extracted and described according to the Criteria for Reporting the Development and Evaluation of Complex 
Interventions in healthcare: revised guideline (CReDECl 2) (Möhler et al., 2015). Study quality ratings were carried out independently by reviewers PD and LW. Any disagreements were recorded and resolved by involvement of an additional reviewer.

\section{Results}

\section{Vision}

Five studies that reported vision interventions for people with dementia were identified (Table 1). Three studies reported on cataract surgery intervention, one on vision rehabilitation training, and one on prism lenses. One study used a prospective controlled design. The remaining studies were case reports or single group intervention studies. All studies were of low to moderate quality; all scored $\leq 15$ on Downs \& Black's (1998) checklist for assessing the quality of randomised and nonrandomised studies. Low quality scores were due to limitations in the quality of reporting, internal validity (bias and confounding), power, and external validity. In relation to the quality of reporting of the intervention according to $\mathrm{CReDECI} 2$ criteria (Table 2), three studies included a theoretical rationale for the intervention (item 1) (Girard et al., 2016; Lerner et al., 2014; Whitson et al., 2013) and two studies reported rationale for specific elements of the intervention (Girard et al., 2016; Whitson et al., 2013). No study reported intended interactions between components (item 3) or consideration of context (item 4). No study reported on feasibility or piloting (item 5). Only two studies reported on elements of evaluation including the strategy for delivering the intervention (item 7), intervention materials (item 8), and fidelity of intervention delivery (item 9) (Girard et al., 2016; Whitson et al., 2013). Only Whitson et al (2013) reported a process evaluation (item 10), external factors that impacted on the intervention (item 12) and some evaluation of resources required (item 13).

(Insert table 1 here)

(Insert table 2 here)

Prism lenses 
Izzo et al. (1986) described the case of a woman with mild dementia following progressive supranuclear palsy prescribed prism lenses. An anecdotal description of improvement in reading ability and vision in the vertical plane was included.

\section{Vision rehabilitation training}

Whitson et al. (2013) described an evaluation of a single group intervention for patients with macular disease (median better eye visual acuity Snellen 20/160) and mild cognitive deficit (based on performance of a cognitive screening test). The intervention was the Memory or Reasoning Enhanced Low Vision Rehabilitation (MORE-LVR) program. MORE-LVR involved 10 hours of vision rehabilitation training with an occupational therapist including individualised goal-setting and involvement of a friend/family member over 6 weeks. Significant improvements in cognitive function (delayed recall but not immediate recall on the Logical Memory test), improvement in vision-related function (Vision Function Questionnaire-25; Mangione et al., 1998) and improvement in activities of daily living (patient-reported satisfaction with ability to perform 8 instrumental activities of daily living) were found.

\section{Cataract surgery}

Lerner et al. (2014) reported the results of cataract surgery for patients with dementia compared to a control group with dementia. The control group had either declined cataract surgery or were on a waiting list. The mean Mini-mental State Examination (MMSE; Folstein et al., 1975) score in the intervention group was 18.3, indicating a milder level of cognitive impairment than in the control group which had an average score of 14 . All participants had a cataract in one or both eyes. Mean visual acuity in the better eye was LogMAR 0.336 for the intervention and 0.381 for the control group. No significant decline in MMSE score in the intervention group six months after pre-surgery baseline assessment was observed, however, in the nonintervention control group, a decline in cognition was seen (corresponding to -0.54 MMSE points/year in the intervention group and -3.3 points/year in the intervention group). Furthermore, a significant reduction in neuropsychiatric symptoms (assessed with the Neuropsychiatric Inventory; NPI; Cummings et al., 1994) in the intervention 
group was seen, compared with the control group which had a significant increase in these symptoms (NPI score from $\sim 11$ to $\sim 6$ in the intervention group versus $\sim 15$ to $\sim 19$ in the control group. Approximate values are reported from a figure). There was a significant reduction in caregiver distress due to neuropsychiatric symptoms (as per the NPI's 'caregiver distress' scale) in the intervention group (from 6 to $\sim 3$ ), with no significant change in the level of caregiver distress in the control group (from $\sim 6$ to $~ 7)$. A range of ophthalmologic adverse events in the intervention group was reported, although it was not clear whether these adverse events were higher than expected.

Girard et al. (2016) reported a single group intervention study of cataract surgery with people with mild to severe dementia (based on evaluation with the MMSE and Alzheimer's Disease Assessment Scale-Cognitive Subscale; ADAS-COG; Graham et al., 2004) and bilateral cataracts with visual acuity in the better eye poorer than LogMAR 0.3. Patients reported a significant increase on the NPI agitation sub-scale (from 0.92 to 2.07). Both patients and caregivers reported statistically significant improvements in sleep problems on the NPI sleep sub-scale (Patients: 1.55 to 0.65; Caregivers: 0.6 to 0.36$)$. No difference in either patient or caregiver completed NPI total score between baseline and three months after surgery was reported.

Finally, Payal et al. (2016) reported improvements in vision-related quality of life accompanied improvements in visual acuity following cataract surgery in a single group of veterans with dementia or cognitive impairment (Visual Function Questionnaire-25; Mangione et al., 1998; scores not reported). Improvements in visual acuity and vision-related quality of life were similar to those among veterans without cognitive impairment.

\section{Hearing}

Twelve papers that reported on ten separate studies of hearing interventions for people with dementia were identified (Table 3). Six studies reported on hearing aid provision, one study on hearing aid 'trouble shooting', one study on provision of assistive listening devices, one study on provision of assistive listening devices plus information on hearing loss and communication training and one study on cochlear implantation interventions. One high quality randomised controlled trial was 
identified. The remaining studies were case reports, single subject design or pre-post test single group design. As with the studies of vision interventions above, most studies were of low to moderate quality ( $\leq 18$ on Downs \& Black's (1998) checklist for assessing the quality of randomised and non-randomised studies). In relation to the quality of reporting according to CReDECI 2 criteria (Table 4), all studies included a theoretical rationale (item 1) and most provided a rationale for specific elements of the intervention (item 2). No study reported on pilot or feasibility testing (item 5). Two studies provided a rationale for the control/comparison condition (item 6) (Palmer et al., 1999; Palmer et al., 1998), and one study provided a description but no rationale for the control condition (Adrait et al., 2017; Nguyen et al., 2017). Only two studies reported a strategy for the delivery (item 7) (Haque, 2012; Mamo et al., 2017) and six studies included a full or partial description of the intervention materials (item 8) (Adrait et al., 2017; Allen et al., 2003; Hopper et al., 2016; Mamo et al., 2017; Nguyen et al., 2017; Palmer et al., 1999; Palmer et al., 1998). No study reported on the fidelity of intervention delivery (item 9) and only two studies conducted a partial process evaluation (item 10; with no interpretation in relation to a theoretical basis; Mamo et al., 2017; Palmer et al., 1998). Only two studies reported on the impact of internal (item 11) (Palmer et al., 1998) and external (item 12) (Haque, 2012; Palmer et al., 1998) factors that impacted on the intervention. No study reported on the costs or resources required (item 13).

(insert table 3)

(insert table 4)

\section{Hearing aids}

Palmer et al. (1998) described the case of a man with moderate dementia (MMSE score 18) with moderate-to-severe sensorineural bilateral hearing loss (mean threshold $64.2 \mathrm{~dB} \mathrm{HL}$ over $250-8,000 \mathrm{~Hz}$ ) who was fitted with a unilateral in-the-ear style hearing aid. An improvement in neuropsychiatric behaviours was seen. The neuropsychiatric assessment was based on informal observations of five problematic behaviours identified by the caregiver using the Behavioral Pathology in Alzheimer's Disease Rating Scale (BEHAVE-AD; Reisberg et al., 1987) questionnaire and with 
charting of the behaviours using a single-subject continuous assessment $A B A B$ design (the hearing aid worn for three weeks, then withdrawn for repairs for one week and returned for the final six weeks of the study). The frequency of problematic behaviours was continuously assessed throughout. The authors reported a clinically significant reduction in hearing disability based on both patient and caregiver report (Hearing Handicap Inventory), before and after the provision of the hearing aid (improvement of $\sim 25$ to $\sim 10$ for patient-reported and $\sim 40$ to $\sim 0$ for spouse-reported Hearing Handicap Inventory scores. Approximate values are reported from a figure).

Palmer et al. followed their single case study with a subsequent report of eight participants with moderate to severe dementia (MMSE range 5-18) with mild to moderate symmetrical bilateral sensorineural hearing impairment (mean threshold 50.7 dB HL over 250-8,000 Hz) (Palmer et al., 1999). As with the single case study, multiple observations of neuropsychiatric behaviours were made pre- and posthearing aid fitting with a unilateral in-the-ear style hearing aid. A significant reduction in between one to four problematic behaviours was identified by the caregiver for each participant using the BEHAVE-AD questionnaire. Seven out of eight caregivers reported a clinically significant reduction in hearing disability (using the Hearing Handicap Inventory) before and after hearing aid fitting.

Allen et al. (2003) reported on a single group intervention involving provision of a unilateral behind-the-ear style hearing aid for people with moderate dementia (mean MMSE score, 18) and pure tone audiometric thresholds greater than $40 \mathrm{~dB} \mathrm{HL}$. Poorer cognitive function between baseline and 24 weeks post-hearing aid fitting was seen (mean MMSE score declined to 16). However, the authors estimated that there was a reduction in the rate of cognitive decline, compared to the estimated rate of cognitive decline for populations with similar severity of cognitive impairment based on MMSE and Euro- Alzheimer's Disease Assessment Scale (Verhey et al., 2004) normative performance. There was no significant change in neuropsychiatric symptoms (using the Manchester and Oxford Universities Scale for the Psychopathological Assessment of Dementia; MOUSEPAD; Allen et al., 1996). There was a significant reduction in hearing related disability (using the Nursing Home Hearing Handicap Index for patient and carer; Schow and Nerbonne, 1977). There was no significant change in activities of daily living (using the Instrumental 
Deterioration for Daily Living in Dementia scale (Barberger-Gateau et al., 1992) nor caregiver burden based on NPI Carer burden and Carer strain scales). By the end of the study, $56 \%$ of the sample reported using their hearing aids either every day or most days. The authors reported statistically significantly less hearing disability for those who used their hearing aids every day versus those who used hearing aids less often, but no difference on any other outcome measure was seen.

Hutchinson et al. (2012a; 2012b) described eight cases of people with dementia and mild-to-severe hearing impairment who were fitted with bilateral behind-the-ear style hearing aids. The severity of dementia was reported in terms of the research audiologist's clinical impression, which ranged from 'no dementia' to 'moderate'. Eight participants were reported to have completed the study, although data from ten participants were presented in relation to the neuropsychiatric symptoms outcome measure. A reduction in neuropsychiatric symptoms 30 days after hearing aid fitting (based on recording of three problematic behaviours that were identified by the caregiver using a version of the BEHAVE-AD questionnaire, which was incorrectly attributed to Palmer et al. (1998)) was observed. No data were provided other than that neuropsychiatric symptoms were 'less' for each participant post hearing aid fitting. The authors also reported numerical increases in scores on a quality of life measure (Life Satisfaction Scale; Deiner et al., 1985) before and after hearing aid fitting.

Haque et al. (2012) described the case of a female resident of a care home with moderate stage dementia due to Alzheimer disease who was used a unilateral behind-the-ear style hearing aid. The most recent MMSE score recorded was 12 . No audiometric hearing data were reported. Following an incident of acute agitation and visual hallucinations, a hearing evaluation revealed that the hearing aid was not functional due to a flat battery. Once hearing aid batteries were changed regularly, no further episodes of agitation or hallucination occurred.

Ghiringhelli et al. (2013) reported on a single group intervention involving provision of hearing aids. Participants were reported to have dementia due to Alzheimer disease and mild to moderate symmetrical bilateral sensorineural hearing loss (mean thresholds over 500, 1000 and $2000 \mathrm{~Hz}$ ranged from 26 to $70 \mathrm{~dB} \mathrm{HL}$ ). Severity of 
dementia was not reported. Neither the style or model of hearing aid nor whether hearing aids were unilaterally or bilaterally fitted was reported. However, participants received hearing aids with either fast or slow release times. 'Release time' refers to how quickly a hearing aid responds to changes in input levels by decreasing or increasing gain. The advantage of a short release time is that the hearing aid quickly returns to normal levels of gain, although short release times may worsen sound quality. Long release times facilitate sound quality but may result in some signal (e.g. on-going speech) being under-amplified, with adverse impact on speech recognition. The study found a significant reduction in hearing disability (HHIE) compared to baseline, 4 months after hearing aid fitting. There were no differences between fast/slow release time subgroups (improvement of $70 \%$ to $25 \%$ for the fast subgroup and $71 \%$ to $26 \%$ for the slow release time subgroup in HHIE scores).

Adrait et al. (2017) and Nguyen et al. (2017) reported the results of a multi-centre double blind randomised placebo-controlled trial of hearing aids with a semi-cross over design. Participants had received a diagnosis of Alzheimer dementia (based on Diagnostic and Statistical Manual of Mental Disorder-IV and National Institute of Neurological and Communicative Disorders and Stroke criteria) with bilateral sensorineural hearing loss (between 21 and $80 \mathrm{~dB} \mathrm{HL}$ ). For the first six months, the active group received bilateral hearing aids, while the placebo group received hearing aids with a small amount of gain to offset the occluding effect of the hearing aid. For the last six months, hearing aids were activated for the placebo group. Cognitive (ADAS-COG, MMSE, 16-item free and cued recall; Grober et al., 2010, digit symbol test; Weschsler, 1997), behavioural and psychological symptoms (NPI), functional ability (instrumental activities of daily living), caregiver and patient quality of life (Zarit Burden Interview, Duke Health Profile; Parkerson et al., 1990, Alzheimers Disease-Related Quality of Life; Rabins et al., 1999) were completed at baseline, six months and 12 months. Hearing aid use was high (83.3\% of active and $62.3 \%$ placebo wore their hearing aids for more than five hours per day). Hearing aid use was more consistent among younger patients, but was not related to cognitive status or severity of hearing impairment. No adverse events related to hearing aids were recorded. Scores on all outcome measures worsened over time. There were no statistically significant differences in any outcome measure between the active and placebo group at six months, or before and after hearing aid activation in the placebo 
group. There was a statistically non-significant trend for lower decline in ADAS-cog and statistically significant improvement in Alzheimers Disease-Related Quality of Life scores for those with high hearing aid use versus low users in the active group.

\section{Assistive listening devices}

Hopper et al. (2016) assessed the impact of provision of assistive listening devices to residents in long-term care facilities with early- to middle-stage dementia and mildto-moderate hearing loss on measures of cognition and communication. The term 'assistive listening device' is used here to refer to personal sound amplification devices. Assistive listening devices provide a basic level of amplification, and may lack the more sophisticated features of hearing aids such as frequency-specific gain. An example of an assistive listening device is the Pocketalker by Williams Sound (https://www.williamssound.com/pocketalker). There was no statistically significant improvement in either cognition (immediate story recall; Mahendra et al., 2005; Clock draw subtest from the Cognitive Linguistic Quick Test; Helm-Estabrooks, 2001) or communication (subtests of the Functional Linguistic Communication Inventory; Bayles and Tomoeda, 1994).

Mamo et al. (2017) also reported on an intervention that involved i) provision of an assistive listening device, ii) provision of information about the impact of hearing impairment and iii) teaching participants and carers about communication strategies. The intervention was delivered to participants who were resident in the community and attending a memory clinic (mean MMSE score = 19.2; mean hearing threshold $48.2 \mathrm{~dB} \mathrm{HL}$ ). Behavioral and psychological symptoms of dementia and caregiver burden were assessed at baseline and one month post intervention. Assistive listening devices were well accepted and used at least some of the time by $74 \%$ of participants, and caregivers reported subjective improvements in engagement and communication. But there was no statistically significant change in behavioural and psychological symptoms of dementia (carer-completed NPI) or caregiver burden (Zarit Burden Interview). Measures of hearing disability were carried out post intervention only and were not analysed statistically.

\section{Cochlear implants}

Modest et al. (2015) included a description of the case of a 70-year-old woman with dementia in the mild stage associated with superficial siderosis. Pure tone 
audiometric thresholds indicated moderate/severe hearing loss in the left ear and profound hearing loss in the right ear. The woman was given a unilateral cochlear implant. There was an immediate subjective improvement in hearing following implantation, however the woman reported no sustained benefit from implantation at follow-up 18 months after implantation. It was observed that the women had experienced significant progression in severity of dementia over the 18 month followup period that may have offset the gains provided by the cochlear implant.

\section{Discussion}

The review identified 17 papers that reported the impact of treating hearing or vision impairment in people with dementia. Studies generally reported improvements in outcome measures post intervention. The present review included grey literature, and inclusion of grey literature may reduce reporting bias (Moher et al., 2009). But it may be that negative outcomes from interventions remain unreported, reflecting a marked reporting bias that is a limitation in our ability to synthesise the evidence. Addressing sensory impairment has promise as a non-pharmacological option for improving outcomes for people with dementia, although there is a clear need to improve the quality of research. Only one high quality randomised controlled trail was reported (Adrait et al., 2017; Nguyen et al., 2017) and only one other study (Lerner et al., 2014) included a control group. All remaining studies were of low-tomoderate quality, and consisted of low-level evidence, such as single case reports, small case series or uncontrolled and underpowered treatment trials. Only five papers (Adrait et al., 2017; Hopper et al., 2016; Mamo et al., 2017; Nguyen et al., 2017; Whitson et al., 2013) reported full statistics that allow the calculation of effect sizes. Most studies reported little information concerning the development, piloting and evaluation of sensory interventions. Limited description of the interventions limits replication and constrains development of an evidence base. A lack of training or educational program as components of the intervention may adversely impact feasibility and fidelity of the intervention.

The most commonly included outcome measures were hearing/vision-related disability and behavioural and psychological symptoms of dementia. Addressing sensory impairments may have additional benefits in other areas (e.g. in relation to cognition, quality of life, functional abilities and caregiver burden) although these 
outcomes were not consistently included across studies. Studies included adults with a range of levels of severity of dementia. However, some studies either did not report the severity of dementia or did not describe the criteria for establishing severity. The subtype of dementia was either described as Alzheimer disease (or superficial siderosis by Modest et al. 2015) or was not reported. The effectiveness of sensory interventions may differ according to severity of dementia and dementia subtype, and so it is problematic that no study reported the outcomes of sensory interventions according to dementia severity or dementia subtype. Analysis of outcomes by severity/subtype was not possible in the present review due to the small numbers of studies in the review and the limitations of reporting.

\section{Hearing interventions}

Hearing interventions mostly involved provision of a hearing aid, with five studies reporting on provision of a hearing aid (Adrait et al., 2017; Allen et al., 2003; Ghiringhelli and lorio, 2013; Hutchinson et al., 2012; Hutchison et al., 2012; Nguyen et al., 2017; Palmer et al., 1999; Palmer et al., 1998), and one additional study reporting on the impact of hearing aid 'trouble shooting' (Haque, 2012). Apart from Adrait et al. (2017), Nguyen et al. (2017), Mamo et al. (2017) and Hopper et al.'s studies, levels of hearing impairment were not reported. However, reassuringly, the diagnosis of hearing impairment was based on audiometric assessment in all the studies reported. Furthermore, all the reported studies of hearing aid interventions found good compliance with hearing aid use across a range of severities of dementia and which were comparable to levels of use reported among non-cognitively impaired new hearing aid users (Aazh et al., 2015). Palmer et al. (1999; 1998) reported selecting a harder to remove in-the-ear style hearing aid rather than a behind-the-ear style aid. However, hearing aid use was reported to be similarly high in studies that reported using behind-the-ear style aids. Allen et al. (2003), Nguyen et al. (2017) and Adrait et al. (2017) reported a tendency for greater improvement in hearing disability, general quality of life and cognition among those who used hearing aids more often compared to those who used them less frequently. Inconsistent or low hearing aid use may reduce the likelihood of detecting any benefit of hearing aids. Studies of non-surgical interventions for sensory impairment should be powered to take non-adherence into account. 
Two studies (Hopper et al., 2016; Mamo et al., 2017) reported on provision of an assistive listening device. Assistive listening devices may have advantages over hearing aids in terms of lower cost (US $\$ 3,000-5,000$ versus $\$ 100-350$ ), accessibility (assistive listening devices may be bought over the counter) and ease of fitting (assistive listening devices do not require fitting by an audiologist). Hopper et al.'s (2016) and Mamo et al.'s (2017) studies suggest that assistive listening devices are well accepted by people with dementia and their carers. The carers in Mamo et al.'s (2017) study reported subjective improvements in communication and engagement, although there were no statistically significant improvements in a psychometric test of communication skills in Hopper et al.'s (2016) study. Hopper et al. (2016) suggested that because participants had relatively mild hearing loss and were tested with and without amplification in ideal quiet conditions, there may have been no additional benefit of amplification on communicative performance. The benefits of assistive listening devices on communication may be apparent in more realistic adverse listening conditions.

Nguyen et al. (2017), Adrait et al. (2017) and Allen et al.'s (2003) studies were the only studies that reported outcomes related to cognitive function, activities of daily living and caregiver burden. However, none of these studies reported any benefit of hearing aids in relation to these outcomes. Mamo et al. (2017) also reported no reduction in caregiver burden with use of assistive listening devices. Allen et al. (2003) reported some benefit in relation to cognitive decline, but the single group design used in Allen et al.'s (2003) study made it difficult to disentangle any benefit of the intervention from the natural progression of dementia. No impact of hearing aids on cognitive decline was reported in Nguyen et al. (2017) and Adrait et al.'s (2017) more robustly designed randomised controlled study. Four out of six studies of hearing interventions that assessed behavioural and psychological symptoms of dementia reported an improvement (Ghiringhelli and lorio, 2013; Hutchinson et al., 2012; Hutchison et al., 2012; Palmer et al., 1999; Palmer et al., 1998). However, Nguyen et al. (2017) and Adrait et al.'s (2017) randomised controlled trial reported no impact of hearing aids on behavioural and psychological symptoms. The difference in results between Nguyen et al. (2017) and Adrait et al.'s (2017) studies and previous studies may be due to the lack of a control group in the latter. All five studies that assessed hearing disability reported immediate improvement following 
intervention (Allen et al., 2003; Ghiringhelli and lorio, 2013; Modest et al., 2015; Palmer et al., 1999; Palmer et al., 1998).

Finally, only one study described cochlear implantation in a case study of someone with severe hearing impairment and dementia (Modest et al., 2015). This study reported immediate benefit from the cochlear implant, but no sustained benefit due to progression of dementia (although the patient may presumably have been worse off without the implant). At minimum, this case study provides some evidence that cochlear implantation is feasible for people with dementia and that people with dementia may benefit from cochlear implantation. Two studies reported that cataract surgery was feasible and beneficial for people with dementia (Girard et al., 2016; Lerner et al., 2014). Surgical cochlear implantation may be a similar case to cataract surgery.

\section{Vision interventions}

Three studies reported on the impact of cataract surgery intervention (Girard et al., 2016; Lerner et al., 2014; Payal et al., 2016), one on rehabilitation training (Whitson et al., 2013) and one on use of prism lenses (Izzo et al., 1986). There was limited and inconsistent evidence for the benefit of any vision intervention on any outcome measure. Out of two studies that reported on behavioural and psychological outcomes following cataract surgery, Lerner et al. (2014) reported a reduction in behavioural and psychological symptoms of dementia, while Girard et al. (2016) reported an improvement in sleep problems but an increase in agitation, with no change in total symptoms overall. A recent study reported that cataract was the primary cause of post-refraction vision impairment for $48 \%$ of people with dementia in the UK, while age-related macular degeneration was the primary cause for $36 \%$ (Bowen et al., 2016). Vision impairment was correctable with refraction for $7-14 \%$ of people with dementia (depending on the level of presenting visual acuity). A continued focus on cataract surgery therefore seems indicated. In addition, it would be useful to include studies of the benefits of refractive correction and treatment and management of macular degeneration for people with dementia.

\section{Recommendations for future research}


Given the high prevalence and impact of hearing and vision impairments among people with dementia, there is a need for good quality evidence to inform clinical practice and national policy for dementia care in relation to the diagnosis and management of hearing and vision impairment. There is an urgent need for wellcontrolled intervention studies which include measures of hearing/vision disability, behavioural and psychological symptoms of dementia, cognitive function and rate of decline, quality of life, activities of daily living and caregiver burden.

Unfortunately, most of the studies in the present review did not adequately report participant characteristics, results or study design information in relation to internal and external validity. All studies should refer to reporting standards prescribed by the Consolidated Standards of Reporting Trials (CONSORT) scheme. Use of CONSORT standards would facilitate critical appraisal and interpretation and reduce the influence of bias. Nguyen et al. (2017) and Adrait et al.'s (2017) randomised controlled trial of hearing aids provides a good example of a robustly designed and well-reported study. Additionally, researchers should consider application of process evaluations as part of future trials and rigorous reporting according to the CReDICl2 criteria.

Given the complex nature of combined sensory and cognitive impairment and the likely substantial individual differences in the impact of impairment, as well as the need and the preference for particular types of intervention, it would be desirable to develop complex interventions that could be tailored to individual patterns of impairment and patient preference (Craig et al., 2008). Patient and public input in development of such interventions would likely increase the acceptability and utility of the intervention (Carman et al., 2013). Including health economic measures to test the cost effectiveness of interventions would increase the relevance and impact of the research in relation to service provision. One example of an ongoing effort to address these issues is the European SENSE-Cog project (www.sense-cog.eu), which is fully-powered randomised controlled trial of a complex support intervention for hearing and vision impairment in people with dementia and concurrent hearing and/or vision impairment (Regan et al., under review). The trial, which is taking place in five countries, will assess efficacy on a range of dementia-related outcomes (i.e. quality of life, caregiver burden, neuropsychiatric symptoms), as well as costeffectiveness. The intervention was carefully developed according to guidance for 
the development of complex psychosocial interventions (Leroi et al., 2017) and has been field trialled for feasibility and acceptability (Regan et al., 2017).

\section{Summary}

The 17 studies identified in this review provide some evidence that hearing and vision-enhancing interventions for people with dementia are feasible and may provide benefit, particularly in relation to improving hearing/vision disability and reducing behavioural and psychological symptoms of dementia. There is limited evidence for sensory interventions in relation to cognitive function, rate of cognitive decline, quality of life, activities of daily living, or caregiver burden. Sensory impairments are very common in people with dementia and exacerbate disability and burden on carers. Sensory impairments are easily identifiable, and relatively low-cost effective interventions are readily available. Actively identifying and treating sensory impairments among people with dementia may be an easy, effective and costefficient method of improving quality of life for people with dementia and their caregivers and reducing health care costs for people with dementia. Future research should include better quality reporting, consistent use of an inclusive range of relevant outcomes and more robust study designs to establish the benefit of sensory interventions to improve outcomes for people with dementia.

\section{Conflicts of interest}

None.

\section{Description of authors' roles}

I. Leroi and P. Dawes are principal investigators of the SENSE-Cog project. Authors P. Dawes, L.Wolski, I. Himmelsbach and J. Regan contributed to screening and selection of included papers. All authors contributed to the writing of the paper and have approved the final version.

\section{Acknowledgements}

This review is part of the Work Package 3 of the SENSE-Cog project, which has received funding from the European Union's Horizon 2020 research and innovation programme under grant agreement no. 668648 . 


\section{References}

Aazh, H., Prasher, D., Nanchahal, K. and Moore, B. C. (2015). Hearing-aid use and its determinants in the UK National Health Service: A cross-sectional study at the Royal Surrey County Hospital. . International Journal of Audiology, 54, 152-161.

Adrait, A., et al. (2017). Do hearing aids influence behavioral and psychological symptoms of dementia and quality of life in hearing impaired Alzheimer's disease patients and their caregivers? Journal of Alzheimer's Disease, (Preprint), 1-13.

Allen, N. H., et al. (2003). The effects of improving hearing in dementia. Age and Ageing, 32, 189-193.

Allen, N. H., Gordon, S., Hope, T. and Burns, A. (1996). Manchester and Oxford Universities Scale for the Psychopathological Assessment of Dementia (MOUSEPAD). The British Journal of Psychiatry, 169, 293-307.

Alzheimer's Disease International (2016). World Alzheimer Report 2016. Improving healthcare for people living with dementia. London: Alzheimer's Disease International.

Alzheimer's Society (2015). Finacial cost of dementia.

Arksey, H. and O'Malley, L. (2005). Scoping studies: towards a methodological framework. International journal of social research methodology, 8, 19-32.

Barberger-Gateau, P., Commenges, D., Gagnon, M., Letenneur, L., Sauvel, C. and Dartigues, J. F. (1992). Instrumental activities of daily living as a screening tool for cognitive impairment and dementia in elderly community dwellers. Journal of the American Geriatrics Society, 40, 1129-1134.

Bayles, K. A. and Tomoeda, C. K. (1994). The functional linguistic communication inventory: Pro-Ed.

Bowen, M., et al. (2016). The Prevalence of Visual Impairment in People with Dementia (the PrOVIDe study): a cross sectional study of 60-89 year old people with dementia and qualitative exploration of individual, carer and professional perspectives. Southampton: National Institute of Health Research.

Brenner, M. H., Curbow, B., Javitt, J. C., Legro, M. W. and Sommer, A. (1993). Vision change and quality of life in the elderly: response to cataract surgery and treatment of other chronic ocular conditions. Archives of ophthalmology, 111, 680-685.

Carman, K. L., et al. (2013). Patient and family engagement: a framework for understanding the elements and developing interventions and policies. Health Affairs, 32, 223-231.

Chao, T. K. and Chen, T. H. H. (2008). Cost-effectiveness of hearing aids in the hearingimpaired elderly: a probabilistic approach. Otology \& Neurotology, 29, 776-783.

Chisolm, T., et al. (2007). A systematic review of health-related quality of life and hearing aids: Final report of the American Academy of Audiology task force on the health-related quality of life benefits of amplification in adults. Journal of the American Academy of Audiology, 18, 151-183.

Cohen-Mansfield, J. and Taylor, J. W. (2004). Hearing aid use in nursing homes, Part 1: Prevalence rates of hearing impairment and hearing aid use. Journal of the American Medical Directors Association, 5, 283-288.

Cooper, C., et al. (2012). Systematic review of the effectiveness of non-pharmacological interventions to improve quality of life of people with dementia. International

Psychogeriatrics, 24, 856-870. 
Craig, P., Dieppe, P., Macintyre, S., Michie, S., Nazareth, I. and Petticrew, M. (2008). Developing and evaluating complex interventions: the new Medical Research Council guidance. BMJ, 337, a1655.

Cummings, J. L., Mega, M., Gray, K., Rosenberg-Thompson, S., Carusi, D. A. and Gornbein, J. (1994). The Neuropsychiatric Inventory comprehensive assessment of psychopathology in dementia. Neurology, 44, 2308-2308.

Davis, K., Drey, N. and Gould, D. (2009). What are scoping studies? A review of the nursing literature. International journal of nursing studies, 46, 1386-1400.

Diener, E. D., Emmons, R. A., Larsen, R. J. and Griffin, S. (1985). The satisfaction with life scale. Journal of personality assessment, 49, 71-75.

Douglas, S., James, I. and Ballard, C. (2004). Non-pharmacological interventions in dementia. Advances in psychiatric treatment, 10, 171-177.

Dupuis, K., Lemke, U., Reed, M. and Pichora-Fuller, K. M. (2016). Treatment of hearing impairment in older adults with cognitive impairment: Importance of including significant others. Alzheimer's \& Dementia, 12, P800-P801.

Folstein, M. F., Folstein, S. E. and McHugh, P. R. (1975). "Mini-mental state": a practical method for grading the cognitive state of patients for the clinician. Journal of Psychiatric Research, 12, 189-198.

Furlong, W. J., Feeny, D. H., Torrance, G. W. and Barr, R. D. (2001). The Health Utilities Index $\left(\mathrm{HUI}^{\circledR}\right)$ system for assessing health-related quality of life in clinical studies. Annals of medicine, 33, 275-384.

Ghiringhelli, R. and lorio, M. C. M. (2013). Hearing aids and recovery times: a study according to cognitive status. Brazilian journal of otorhinolaryngology, 79, 177-184.

Girard, B., Chouard, B., Levy, P., Luquel, L., Seux, M. L. and Drunat, O. (2016).

Neuropsychological benefit of cataract surgery among sight impaired Alzheimers patient. Journal francais d'optalmologie, 39, 675-686.

Graham, D. P., Cully, J. A., Snow, A. L., Massman, P. and Doody, R. (2004). The Alzheimer's Disease Assessment Scale-Cognitive subscale: normative data for older adult controls.

Alzheimer Disease \& Associated Disorders, 18, 236-240.

Grober, E., Sanders, A. E., Hall, C. and Lipton, R. B. (2010). Free and cued selective reminding identifies very mild dementia in primary care. Alzheimer disease and associated disorders, 24, 284-290.

Haque, R., Abdelrehman, N., \& Alavi, Z. (2012). "There's a Monster Under My Bed": Hearing Aids and Dementia in Long-Term Care Settings. Annal of Long-term Care, August, 28-33.

Helm-Estabrooks, N. (2001). Cognitive Linguistic Quick Test. San Antonio, TX: Pearson Education.

Heyl, V. and Wahl, H. (2012). Managing daily life with age-related sensory loss: Cognitive resources gain in importance. Psychology and Aging, 27, 510.

Hopper, T., Slaughter, S. E., Hodgetts, B., Ostevik, A. and Ickert, C. (2016). Hearing Loss and Cognitive-Communication Test Performance of Long-Term Care Residents With Dementia: Effects of Amplification. Journal of Speech, Language, and Hearing Research, 59, 1533-1542. Horowitz, A. (2004). The prevalence and consequences of vision impairment in later life. Topics in Geriatric Rehabilitation, 20, 185-195.

Hutchinson, B., Covan, E. K. and Bogus, J. C. (2012). Presbycusis, Part 2: Can you hear the music of life? Care Management Journals, 13, 200-208. 
Hutchison, B., Covan, E. K. and Bogus, J. C. (2012). Presbycusis, part 1: can you hear the music of life? Care Management Journals, 13, 148-172.

Izzo, K. L., DiLorenzo, P. and Roth, A. (1986). Rehabilitation in progressive supranuclear palsy: case report. . Archives of Physical Medicine Rehabilitation, 67, 473-476.

Lansingh, V. C., Carter, M. J. and Martens, M. (2007). Global cost-effectiveness of cataract surgery. Opthalmology, 114, 1670-1678.

Lerner, A. J., et al. (2014). Improved vision, cognition and neuropsychiatric symptoms following cataract surgery in subjects with dementia. Alzheimer's Association International Conference Copenhagen, Denmark.

Leroi, I., et al. (2017). Research protocol for a complex intervention to support hearing and vision function to improve the lives of people with dementia. Pilot and feasibility studies, 3 , 38.

Mahendra, N., Bayles, K. A. and Harris, F. P. (2005). Effect of presentation modality on immediate and delayed recall in individuals with Alzheimer's disease. American Journal of Speech-Language Pathology and Audiology, 14, 144-155.

Mamo, S. K., et al. (2017). Hearing Care Intervention for Persons with Dementia: A Pilot Study. . The American journal of geriatric psychiatry, 25, 91-101.

Mangione, C. M., Lee, P. P., Pitts, J., Gutierrez, P., Berry, S. and Hays, R. D. (1998).

Psychometric properties of the National Eye Institute visual function questionnaire (NEIVFQ). Archives of ophthalmology, 116, 1496-1504.

Modest, M. C., Carlson, M. L., Wanna, G. B. and Driscoll, C. L. (2015). Cochlear Implantation in Patients With Superficial Siderosis: Seven Cases and Systematic Review of the Literature. Otology \& Neurotology, 36, 1191-1196.

Moher, D., Liberati, A., Tetzlaff, J., Altman, D. G. and Prisma Group (2009). Preferred reporting items for systematic reviews and meta-analyses: the PRISMA statement. PLoS medicine, 6, e1000097.

Möhler, R., Köpke, S. and Meyer, G. (2015). Criteria for Reporting the Development and Evaluation of Complex Interventions in healthcare - revised guideline (CReDECI 2). Trials, 16, 204.

Morse, A. R., Teresi, J., Rosenthal, B., Holmes, D. and Yatzkan, E. S. (2004). Visual Acuity Assessment in Persons with Dementia. Research Report. Journal of Visual Impairment \& Blindness, 98, 560-577.

Nguyen, M. F., et al. (2017). Efficacy of hearing aids on the cognitive status of patients with Alzheimer's disease and hearing loss: A multicenter controlled randomized trial. , . Journal of Alzheimer's Disease, (Preprint), 1-15.

OCEBM Levels of Evidence Working Group (2011). The Oxford 2011 Levels of Evidence.

Oxford Centre for Evidence-Based Medicine.

Palmer, C. V., Adams, S. W., Bourgeois, M., Durrant, J. and Rossi, M. (1999). Reduction in caregiver-identified problem behaviors in patients with Alzheimer disease post-hearing-aid fitting. Journal of Speech, Language and Hearing Research, 42, 312-328.

Palmer, C. V., Adams, S. W., Durrant, J. D., Bourgeois, M. and Rossi, M. (1998). Managing hearing loss in a patient with Alzheimer disease. Journal of the American Academy of Audiology, 9, 275-284.

Parkerson, G. R., Broadhead, W. E. and Tse, C. K. J. (1990). The Duke Health Profile: A 17item measure of health and dysfunction. Medical care, Nov, 1056-1072. 
Payal, A. R., et al. (2016). Visual outcomes and vision-related quality of life in veterans with dementia or cognitive impairment: Results from the Veterans Affairs Ophthalmic Surgery Outcomes Data Project ARVO Annual Meeting Seattle, Washington.

Petersen, R. C. (2011). Mild cognitive impairment. New England Journal of Medicine, 364, 2227-2234.

Rabins, P. V., Kasper, J. D., Kleinman, L., Black, B. S. and Patrick, D. L. (1999). Concepts and methods in the development of the ADRQL: an instrument for assessing health-related quality of life in persons with Alzheimer's disease. . Journal of Mental Health and Aging, 5, 33-48.

Regan, J., et al. (under review). A randomised controlled trial of sensory intervention in dementia: Protocol for the efficacy and cost-effectiveness of the SENSE-Cog intervention. Trials.

Regan, J., et al. (2017). Improving hearing and vision in dementia: Protocol for a field trial of a new intervention. BMJ open, 7, e018744.

Reisberg, B., Borenstein, J., Salob, S. P., Ferris, S. H., Franssen, E. and Georgotas, A. (1987). Behavioral pathology in Alzheimer's disease rating scale (BEHAVE-AD). Journal of Clinical Psychiatry, 48, 9-15.

Sanchez, T. G., Rocha, S. C. M., Knobel, K. A. B., Kii, M. A., Santos, R. M. R. and Pereira, C. B. (2011). Musical hallucination associated with hearing loss. Arquivos de neuro-psiquiatria, 69, 395-400.

Schow, R. L. and Nerbonne, M. A. (1977). Assessment of hearing handicap by nursing home residents and staff. Journal of the Academy of Rehabilitative Audiology, 10, 2-12.

Strawbridge, W. J., Wallhagen, M. I., Shema, S. J. and Kaplan, G. A. (2000). Negative Consequences of Hearing Impairment in Old Age A Longitudinal Analysis. The Gerontologist, 40, 320-326.

Teunisse, R. J., Zitman, F. G., Cruysberg, J. R. M., Hoefnagels, W. H. L. and Verbeek, A. L. M. (1996). Visual hallucinations in psychologically normal people: Charles Bonnet's syndrome. . The Lancet, 347(9004), 794-797.

Uhlmann, R. F., Rees, T. S., Psaty, B. M. and Duckert, L. G. (1989). Validity and reliabilty of auditory screening tests in dementiaed and non-demented older adults. Journal of general internal medicine, 4, 90-96.

Ventry, I. M. and Weinstein, B. E. (1982). The hearing handicap inventory for the elderly: a new tool. Ear and hearing, 3, 128-134.

Verhey, F. R., et al. (2004). Cross-national comparison and validation of the Alzheimer's Disease Assessment Scale: results from the European Harmonization Project for Instruments in Dementia (EURO-HARPID). International journal of geriatric psychiatry, 19, 41-50.

Vitale, S., Cotch, M. F., Sperduto, R. and Ellwein, L. (2006). Costs of refractive correction of distance vision impairment in the United States, 1999-2002. Opthalmology, 113, 21632170.

Wechsler, D. (1997). Wechsler Adult Intelligence Scale - Third Edition. Oxford: Pearson Assessment

Whitson, H. E., et al. (2013). A low-vision rehabilitation program for patients with mild cognitive deficits. JAMA ophthalmology, 131, 912-919.

Zarit, S. H., Orr, N. K. and Zarit, J. M. (1985). The hidden victims of Alzheimer's disease: Families under stress: NYU Press. 


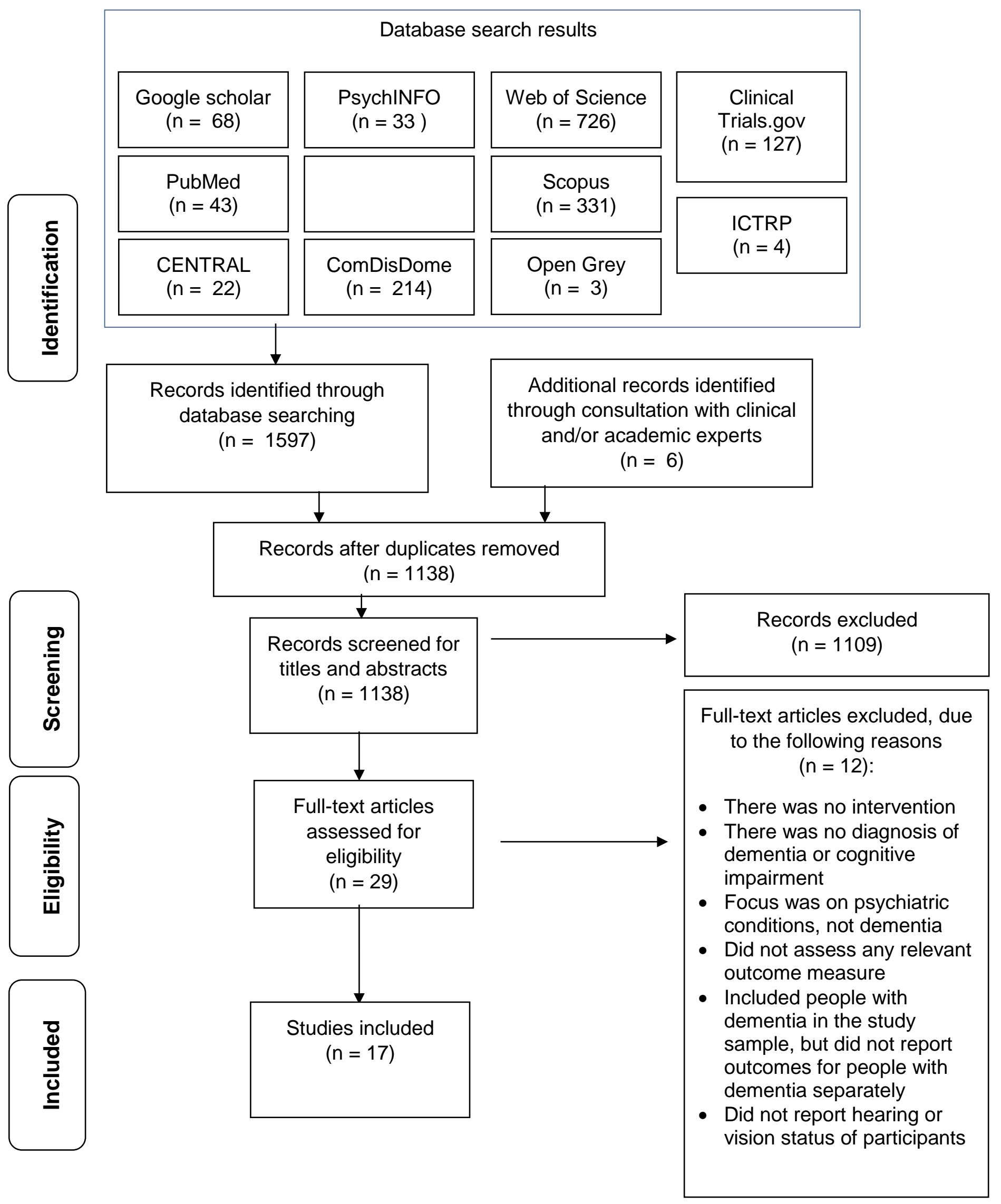


Table 1. Vision interventions for people with dementia

\begin{tabular}{|c|c|c|c|c|c|c|c|c|c|c|c|}
\hline \multirow[t]{2}{*}{ Author } & \multirow{2}{*}{$\begin{array}{c}\text { Study } \\
\text { design } \\
\text { (level of } \\
\text { evidence }^{*} \text { ) }\end{array}$} & \multirow{2}{*}{$\begin{array}{l}\text { Study } \\
\text { quality } \\
\text { rating }\end{array}$} & \multirow[t]{2}{*}{ Participants } & \multirow[t]{2}{*}{ Intervention } & \multicolumn{7}{|c|}{ Outcome } \\
\hline & & & & & Cognition & $\begin{array}{l}\text { Rate of cognitive } \\
\text { decline }\end{array}$ & $\begin{array}{l}\text { Behavioural and } \\
\text { psychological } \\
\text { symptoms }\end{array}$ & $\begin{array}{l}\text { Vision related } \\
\text { disability }\end{array}$ & $\begin{array}{l}\text { General quality } \\
\text { of life }\end{array}$ & $\begin{array}{l}\text { Activities of } \\
\text { daily living }\end{array}$ & $\begin{array}{l}\text { Caregiver } \\
\text { burden }\end{array}$ \\
\hline $\begin{array}{l}\text { Izzo et al. } \\
(1986)\end{array}$ & $\begin{array}{l}\text { Case report } \\
\text { (level 5) }\end{array}$ & 6 & $\mathrm{~N}=1$ & Prism lenses & - & - & - & Improvement & - & - & - \\
\hline $\begin{array}{l}\text { Whitson et } \\
\text { al (2013) }\end{array}$ & $\begin{array}{l}\text { Pre-post } \\
\text { test single } \\
\text { group } \\
\text { intervention } \\
\text { (level 4) }\end{array}$ & 14 & $\mathrm{~N}=12$ & $\begin{array}{l}\text { MORE-VLR; } 10 \\
\text { hours vision } \\
\text { rehabilitation } \\
\text { training with an } \\
\text { occupational } \\
\text { therapist }\end{array}$ & $\begin{array}{l}\text { Improvement } \\
\text { (Logical Memory } \\
\text { test, delayed } \\
\text { recall; } d=0.53 \text { ) }\end{array}$ & - & - & $\begin{array}{l}\text { Improvement } \\
\text { (VFQ-25; } d= \\
0.50)\end{array}$ & - & $\begin{array}{c}\text { Improvement } \\
\text { (Patient } \\
\text { satisfaction with } \\
\text { IADL ability; } \\
d=0.68)\end{array}$ & - \\
\hline $\begin{array}{l}\text { Lerner et } \\
\text { al }(2014) \dagger\end{array}$ & $\begin{array}{l}\text { Prospective } \\
\text { controlled } \\
\text { trial (not } \\
\text { randomized } \\
\text { ) (level 2) }\end{array}$ & 12 & $\begin{array}{l}\mathrm{N}=43 \\
\text { (intervention } \\
\text { ) and } \mathrm{N}=18 \\
\text { (control). }\end{array}$ & Cataract surgery & - & Improvement & Improvement & - & - & - & Improvement \\
\hline $\begin{array}{l}\text { Girard et } \\
\text { al. (2016) }\end{array}$ & $\begin{array}{l}\text { Pre-post } \\
\text { test single } \\
\text { group } \\
\text { intervention } \\
\text { (level 4) }\end{array}$ & 12 & $\mathrm{~N}=38$ & Cataract surgery & - & - & $\begin{array}{l}\text { No change in total } \\
\text { NPI score, } \\
\text { Increased } \\
\text { agitation, } \\
\text { Improved sleep } \\
\text { problems }\end{array}$ & - & - & - & - \\
\hline $\begin{array}{l}\text { Payal et } \\
\text { al. }(2016) \ddagger\end{array}$ & $\begin{array}{l}\text { Retrospecti } \\
\text { ve single } \\
\text { group study } \\
\text { (level 4) }\end{array}$ & 9 & $\mathrm{~N}=93$ & Cataract surgery & - & - & - & Improvement & - & - & - \\
\hline
\end{tabular}

*Based on the Oxford 2011 Levels of Evidence (OCEBM Levels of Evidence Working Group 2011)

+Conference poster presentation

$\ddagger$ Conference abstract 
Table 2. Evaluation of vision intervention studies for people with dementia using the CReDECI 2 checklist

\begin{tabular}{|c|c|c|c|c|c|c|c|}
\hline & & Description of.. & $\begin{array}{l}\text { Izzo et al. } \\
\quad(1986)\end{array}$ & $\begin{array}{l}\text { Whitson et } \\
\text { al (2013) }\end{array}$ & $\begin{array}{l}\text { Lerner et al } \\
\quad(2014)\end{array}$ & $\begin{array}{l}\text { Girard et } \\
\text { al. }(2016)\end{array}$ & $\begin{array}{l}\text { Payal et al. } \\
\quad(2016)\end{array}$ \\
\hline \multirow{4}{*}{ 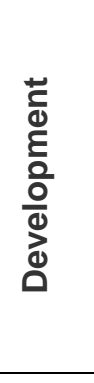 } & 1 & the intervention's underlying theoretical basis & No & Yes (p. 913) & Yes & Yes (p. 676) & No \\
\hline & 2 & intervention components, selection reasons, functions & No & $\begin{array}{l}\text { Yes (p. 913- } \\
\text { 914) }\end{array}$ & No & Yes (p. 677) & No \\
\hline & 3 & intended interactions between different components & No & No & No & No & No \\
\hline & 4 & consideration of the context's characteristics & No & No & No & No & No \\
\hline 흠 음 & 5 & the pilot test and its impact on the definite intervention & No & No & No & No & No \\
\hline \multirow{8}{*}{ 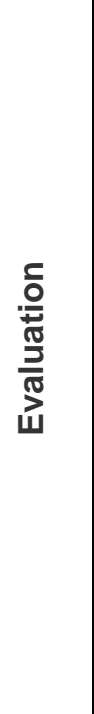 } & 6 & the control condition and reasons for the selection & No & No & Partial & No & Partial \\
\hline & 7 & $\begin{array}{l}\text { the strategy for delivering the intervention within the } \\
\text { study context }\end{array}$ & No & $\begin{array}{c}\text { Yes (p. 913- } \\
914)\end{array}$ & No & Yes (p. 677) & No \\
\hline & 8 & all materials or tools used delivery the intervention & No & Yes (p. 914) & No & Yes (p. 677) & Partial \\
\hline & 9 & $\begin{array}{l}\text { fidelity of the delivery process compared the study } \\
\text { protocol }\end{array}$ & No & Yes (p. 915) & No & Yes (p. 677) & No \\
\hline & 10 & a process evaluation and underlying theoretical basis & No & $\begin{array}{l}\text { Partial (p. } \\
915)\end{array}$ & No & No & No \\
\hline & 11 & internal facilitators and barriers & No & No & No & No & No \\
\hline & 12 & external conditions or factors & No & Yes (p. 915) & No & No & No \\
\hline & 13 & $\begin{array}{l}\text { costs or required resources for the delivery of } \\
\text { intervention }\end{array}$ & No & $\begin{array}{l}\text { Partial (p. } \\
917)\end{array}$ & No & No & No \\
\hline
\end{tabular}


Table 3. Hearing interventions for people with dementia

\begin{tabular}{|c|c|c|c|c|c|c|c|c|c|c|c|}
\hline \multirow[t]{2}{*}{ Author } & \multirow{2}{*}{$\begin{array}{l}\text { Study design } \\
\text { (level of } \\
\text { evidence }^{\star} \text { ) }\end{array}$} & \multirow{2}{*}{$\begin{array}{l}\text { Study } \\
\text { quality } \\
\text { rating }\end{array}$} & \multirow[t]{2}{*}{ Participants } & \multirow[t]{2}{*}{ Intervention } & \multicolumn{7}{|c|}{ Outcome } \\
\hline & & & & & Cognition & $\begin{array}{c}\text { Rate of } \\
\text { cognitive } \\
\text { decline }\end{array}$ & $\begin{array}{l}\text { Behavioural } \\
\text { and } \\
\text { psychological } \\
\text { symptoms }\end{array}$ & $\begin{array}{l}\text { Hearing } \\
\text { related } \\
\text { disability }\end{array}$ & $\begin{array}{c}\text { General } \\
\text { quality of life }\end{array}$ & $\begin{array}{c}\text { Activities of } \\
\text { daily living }\end{array}$ & $\begin{array}{c}\text { Caregiver } \\
\text { burden }\end{array}$ \\
\hline $\begin{array}{l}\text { Palmer } \\
\text { et al. (1998) }\end{array}$ & $\begin{array}{l}\text { Single subject } \\
\text { multiple baseline } \\
\text { design (level 5) }\end{array}$ & 11 & $\mathrm{~N}=1$ & Hearing aid & - & - & Improvement & Improvement & - & - & - \\
\hline $\begin{array}{l}\text { Palmer } \\
\text { et al. (1999) }\end{array}$ & $\begin{array}{l}\text { Case series } \\
\text { multiple baseline } \\
\text { design (level 4) }\end{array}$ & 18 & $\mathrm{~N}=8$ & Hearing aid & - & - & Improvement & Improvement & - & - & - \\
\hline $\begin{array}{l}\text { Allen } \\
\text { et al. (2003) }\end{array}$ & $\begin{array}{l}\text { Pre-post test } \\
\text { single group } \\
\text { intervention (level } \\
4 \text { ) }\end{array}$ & 15 & $\mathrm{~N}=31$ & Hearing aid & Worse & Improvement & No benefit & Improvement & - & Worse & No benefit \\
\hline $\begin{array}{l}\text { Hutchinson } \\
\text { et al } \\
\text { (2012a; } \\
2012 \mathrm{~b})\end{array}$ & $\begin{array}{l}\text { Case series (level } \\
\text { 4) }\end{array}$ & 5 & $\mathrm{~N}=8$ & Hearing aid & - & - & Improvement & - & Improvement & - & - \\
\hline $\begin{array}{l}\text { Haque } \\
\text { et al. (2012) }\end{array}$ & $\begin{array}{l}\text { Case report (level } \\
\text { 5) }\end{array}$ & 10 & $\mathrm{~N}=1$ & $\begin{array}{l}\text { Hearing aid trouble } \\
\text { shooting (battery change) }\end{array}$ & - & - & Improvement & - & - & - & - \\
\hline $\begin{array}{l}\text { Ghiringhelli } \\
\text { et al. } \\
\text { (2013) }\end{array}$ & $\begin{array}{l}\text { Pre-post test } \\
\text { single group } \\
\text { intervention (level } \\
\text { 4) }\end{array}$ & 13 & $\mathrm{~N}=26$ & Hearing aid & - & - & - & Improvement & - & - & - \\
\hline $\begin{array}{l}\text { Adrait et al. } \\
\text { (2017), } \\
\text { Nguyen et } \\
\text { al. (2017) }\end{array}$ & $\begin{array}{l}\text { Randomised } \\
\text { controlled trial } \\
\text { (level 1) }\end{array}$ & 30 & $\mathrm{~N}=51$ & Hearing aid & No benefit & No benefit & No benefit & - & No benefit & No benefit & No benefit \\
\hline $\begin{array}{l}\text { Hopper et } \\
\text { al. (2016) }\end{array}$ & $\begin{array}{l}\text { Pre-post test } \\
\text { single group } \\
\text { intervention (level } \\
4 \text { ) }\end{array}$ & 23 & $\mathrm{~N}=31$ & Assistive listening device & No benefit & - & - & No benefit & - & - & - \\
\hline $\begin{array}{l}\text { Mamo et al. } \\
\text { (2017) }\end{array}$ & $\begin{array}{l}\text { Pre-post test } \\
\text { single group } \\
\text { intervention (level } \\
4 \text { ) }\end{array}$ & 18 & $\mathrm{~N}=20$ & $\begin{array}{l}\text { Assistive listening device } \\
\text { plus provision of } \\
\text { information about the } \\
\text { effects of hearing loss and } \\
\text { communication training }\end{array}$ & - & - & No benefit & - & - & - & No benefit \\
\hline $\begin{array}{l}\text { Modest } \\
\text { et al. (2015) }\end{array}$ & $\begin{array}{l}\text { Case report (level } \\
\text { 5) }\end{array}$ & 9 & $\mathrm{~N}=1$ & Cochlear implant & - & - & - & $\begin{array}{l}\text { Immediate } \\
\text { improvement; } \\
\text { no sustained } \\
\text { benefit }\end{array}$ & - & - & - \\
\hline
\end{tabular}

*Based on the Oxford 2011 Levels of Evidence (OCEBM Levels of Evidence Working Group 2011) 
Table 4. Evaluation of hearing intervention studies for people with dementia using the CReDECI 2 checklist

\begin{tabular}{|c|c|c|c|c|c|c|c|c|c|c|c|c|}
\hline & & Description of... & $\begin{array}{l}\text { Palmer } \\
\text { et al. } \\
(1998)\end{array}$ & $\begin{array}{l}\text { Palmer } \\
\text { et al. } \\
\text { (1999) }\end{array}$ & $\begin{array}{l}\text { Allen } \\
\text { et al. } \\
(2003)\end{array}$ & $\begin{array}{l}\text { Hutchinso } \\
\text { n et al } \\
\text { (2012a; } \\
2012 b)\end{array}$ & $\begin{array}{l}\text { Haque } \\
\text { et al. } \\
(2012)\end{array}$ & $\begin{array}{l}\text { Ghiringhell } \\
\text { i et al. } \\
(2013)\end{array}$ & $\begin{array}{l}\text { Modest } \\
\text { et al. } \\
(2015)\end{array}$ & $\begin{array}{l}\text { Hopper et } \\
\text { al. (2016) }\end{array}$ & $\begin{array}{l}\text { Mamo et } \\
\text { al. (2017) }\end{array}$ & $\begin{array}{l}\text { Adrait et } \\
\text { al. (2017), } \\
\text { Nguyen et } \\
\text { al. (2017) }\end{array}$ \\
\hline \multirow{4}{*}{ 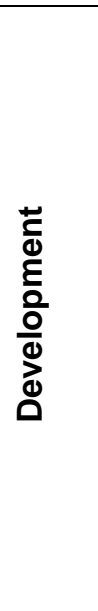 } & 1 & $\begin{array}{l}\text { the intervention's } \\
\text { underlying theoretical } \\
\text { basis }\end{array}$ & $\begin{array}{l}\text { Yes (p. 275- } \\
278)\end{array}$ & $\begin{array}{c}\text { Yes (p. 312- } \\
314)\end{array}$ & $\begin{array}{c}\text { Yes (p. 189- } \\
190)\end{array}$ & $\begin{array}{l}\text { Yes (p. 153 } \\
\text { Hutchinson et } \\
\text { al 2012a) }\end{array}$ & Yes (p. 1) & Yes (p. 178) & Yes (p. 1191) & $\begin{array}{c}\text { Yes (p. 1532- } \\
1534)\end{array}$ & Yes (p. 92) & $\begin{array}{c}\text { Yes (p.2 } \\
\text { Adrait et al } \\
2017 ; p .2-3 \\
\text { Nguyen et al } \\
\text { 2017) }\end{array}$ \\
\hline & 2 & $\begin{array}{l}\text { intervention } \\
\text { components, selection } \\
\text { reasons, functions }\end{array}$ & Yes (p. 277) & Yes (p. 317) & Yes (p. 190) & No & Yes (p. 5) & $\begin{array}{c}\text { Yes (p. 178- } \\
179)\end{array}$ & No & No & Yes (p. 93) & $\begin{array}{c}\text { Yes (p.3 } \\
\text { Adrait et al } \\
2017 ; p .4-5 \\
\text { Nguyen et al } \\
\text { 2017) }\end{array}$ \\
\hline & 3 & $\begin{array}{l}\text { intended interactions } \\
\text { between different } \\
\text { components }\end{array}$ & No & No & No & No & No & No & No & No & No & No \\
\hline & 4 & $\begin{array}{l}\text { consideration of the } \\
\text { context's characteristics }\end{array}$ & No & No & No & No & Yes (p. 1-2) & No & No & No & No & No \\
\hline 흠 옴 & 5 & $\begin{array}{l}\text { the pilot test and its } \\
\text { impact on the definite } \\
\text { intervention }\end{array}$ & No & No & No & No & No & No & No & No & $\begin{array}{l}\text { Yes; paper } \\
\text { describes a } \\
\text { pilot } \\
\text { evaluation }\end{array}$ & No \\
\hline \multirow{4}{*}{ 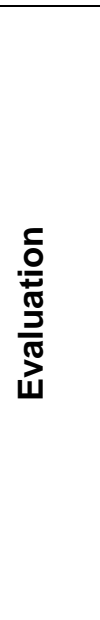 } & 6 & $\begin{array}{l}\text { the control condition } \\
\text { and reasons for the } \\
\text { selection }\end{array}$ & Yes (p 281) & Yes (p. 314) & No & No & No & No & No & No & No & $\begin{array}{c}\text { Partial (p. 3 } \\
\text { Adriat et al } \\
\text { 2017; p. } 4 \\
\text { Nguyen et al } \\
\text { 2017) } \\
\end{array}$ \\
\hline & 7 & $\begin{array}{l}\text { the strategy for } \\
\text { delivering the } \\
\text { intervention within the } \\
\text { study context }\end{array}$ & No & No & No & No & Yes (p. 5-6) & No & No & No & $\begin{array}{c}\text { Yes (p. 93- } \\
94)\end{array}$ & No \\
\hline & 8 & $\begin{array}{l}\text { all materials or tools } \\
\text { used delivery the } \\
\text { intervention }\end{array}$ & Yes (p. 280) & $\begin{array}{c}\text { Yes (p. 317- } \\
318)\end{array}$ & $\begin{array}{c}\text { Partial (p. } \\
190)\end{array}$ & No & No & No & No & Yes (p. 1535) & $\begin{array}{c}\text { Yes (p. 93- } \\
94)\end{array}$ & $\begin{array}{c}\text { Yes (p3 } \\
\text { Adrait et al } \\
\text { 2017; } p 4 \\
\text { Nguyen et al } \\
\text { 2017) } \\
\end{array}$ \\
\hline & 9 & $\begin{array}{l}\text { fidelity of the delivery } \\
\text { process compared the } \\
\text { study protocol }\end{array}$ & No & No & No & No & No & No & No & No & No & No \\
\hline
\end{tabular}


Sensory interventions for people with dementia

\begin{tabular}{|c|c|c|c|c|c|c|c|c|c|c|c|}
\hline 10 & $\begin{array}{l}\text { a process evaluation } \\
\text { and underlying } \\
\text { theoretical basis }\end{array}$ & $\begin{array}{l}\text { Partial (p. } \\
281-282)\end{array}$ & No & No & No & No & No & No & No & Partial (p. 97) & No \\
\hline 11 & $\begin{array}{l}\text { internal facilitators and } \\
\text { barriers }\end{array}$ & Yes (p. 282) & No & No & No & No & No & No & No & No & No \\
\hline 12 & $\begin{array}{l}\text { external conditions or } \\
\text { factors }\end{array}$ & Yes (p. 282) & No & No & No & Yes (p. 3) & No & No & No & No & No \\
\hline 13 & $\begin{array}{l}\text { costs or required } \\
\text { resources for the } \\
\text { delivery of intervention }\end{array}$ & No & No & No & No & No & No & No & No & No & No \\
\hline
\end{tabular}

